\title{
A GENERIC MICROSTRUCTURE-EXPLICIT MODEL OF CREEP IN NICKEL-BASE SUPERALLOYS
}

\author{
H.Basoalto ${ }^{1}$, S.K.Sondhi ${ }^{1,2}$, B.F.Dyson ${ }^{1}$ and M.McLean ${ }^{1}$ \\ ${ }^{1}$ Department of Materials, Imperial College London, Exhibition Road, London, SW7 2AZ, United Kingdom. \\ ${ }^{2}$ National Metallurgical Laboratory, Jamshedpur, India.
}

Key Words: creep, damage, modelling, microstructure, cavitation, coarsening

\begin{abstract}
Past approaches to modelling the creep behaviour of engineering alloys have been either totally empirical or, while having functional forms consistent with current understanding of deformation and fracture mechanisms, have been calibrated by comparison with an available creep database. They have not specifically included quantitative measures of the microstructural features that are thought to impart creep resistance to the alloys. The present paper reviews and extends a microstructure-specific model of creep in particle-strengthened alloys in which the model parameters are directly related to measurable characteristics of the microstructure of nickel-base superalloys. The model accounts for three previously identified changes in microstructure that occur during the creep of superalloys: (i) coarsening of the $\gamma^{\prime}$ precipitate; (ii) the progressive increase in mobile dislocation density with accumulated creep strain; and (iii) the development of grain boundary cavities. The relative dominance of each will be demonstrated using a set of commercial alloys with specific alloy microstructures. It is emphasised that the model-generated curves are true predictions using input microstructural characteristics and are not empirically fitted to the creep data.
\end{abstract}

\section{Introduction}

Superalloys for application as gas turbine blades have been developed over a more than sixty years with the primary aim of increasing their resistance to creep deformation and fracture. When coupled with control of other properties, such as corrosion and thermal fatigue resistance, this has led to a progressive increase in temperature capability with concomitant improvements in engine performance and efficiency. The improved creep performance of precipitation-hardened superalloys has resulted from control of the chemistry and of the grain and precipitate structures.[1] In particular, the volume fraction and solvus temperatures of the $\gamma^{\prime}$ precipitate have increased steadily over the years and the grain morphology has evolved from equiaxed to columnar and eventually to the single crystal form.[2] These have been the dominant factors in the improved creep performance and must ultimately be incorporated in any understanding of the mechanisms of creep.

Although creep has not been an important factor in turbine discs, which are also predominantly produced from nickel-base superalloys, there is a growing concern that as engine temperatures increase further there will be transient periods of operation where creep will significantly influence the service lives of discs. This has been a problem that has been addressed as part of the DARPA Accelerated Insertion of Materials Programme to which the authors have contributed. [3]

The most damaging effect of creep deformation is not simply, or even predominantly, through the time to rupture of macroscopic turbine blades or discs under load at temperature. It also plays an important role in stress relaxation and redistribution during variable stress/temperature and displacement-controlled deformation of these components. It is important to be able to assess the contribution that creep makes during the complex loading histories of superalloys in service. The effective application of sophisticated computer-aided design methods requires that materials behaviour can be represented by reliable constitutive equations that are compatible with the numerical codes used to simulate service response of blades and discs.

There have been many approaches to representing the strain-time evolution of engineering alloys in general and superalloys in particular. These have ranged from the purely empirical $\mathrm{t}^{1 / 3}$ equation for primary creep proposed by Andrade [4] to the fitting of complete creep curves using the expanded power law representation of Graham and Walles [5] and the sum of exponential functions in the $\theta$-projection approach. [6] Extension to cyclic loading has been achieved through a number of viscoelastic formulations, such as those of Chaboche [7] and Cailletaud.[8] There have also been several attempts to develop equations that reflect the mechanisms influencing creep deformation. Kachanov [9] and Rabotnov [10] expressed creep rate as a function of an undefined damage parameter; others extended this approach to the development of equations that reflected specific types of damage that were material and load/temperature specific. [11] All of these approaches lead to multi-parameter representations, which are calibrated against mechanical property data.

Although it is very clear that the progressive enhancement of creep strength of superalloys has been associated with control of critical microstructural features, the parameters in the above models have no immediate quantitative relationship to microstructure. Indeed, there seems to be no means of inferring the effect of even a small change in composition and/or heat treatment of a given alloy on the creep response without repeating the extensive model calibration procedure. Nor do the models recognise that superalloys, and other engineering alloys, have microstructures and thermo-mechanical response that change during exposure at service temperatures and stresses. Indeed, the microstructures of superalloys often vary spatially and temporally as a result of thermal history in heat treatment and service. 
This paper describes the development of a new type of creep model in which the constitutive equations are explicitly expressed in terms of quantitative measures of the initial microstructural features and their subsequent rates of evolution.

\section{Basis of the Model}

The classic theory of Ansell and Weertmen [12] represented creep in particle-strengthened materials as being due to a sequential climb-glide movement of dislocations past the rigid particulate obstacles, which inhibited free glide. Although the model clearly captures most of the physics that even now we recognise must apply in particle-strengthened materials, it only predicts a linear relationship between creep rate and stress for stresses below the Orowan stress. Experimentally, particle strengthened alloys, such as superalloys, exhibit strong stress dependencies of creep with stress exponents of 8 or above, if mapped by a power-law function. Attempts to rationalise this discrepancy by introducing a threshold stress into the power-law equation leads to an increasing stress exponent with decreasing stress, whereas superalloys exhibit a decreasing stress exponent.

Following earlier work by Dyson and Osgerby[13], Dyson [14] suggested that a geometrically random distribution of dislocationparticle intersections will always have a small fraction of dislocations in a position to "escape" after a single climb event and then to glide until again being temporarily trapped at another particle. The probability of a successful "escape", followed by viscous glide until each dislocation is again temporarily trapped at another particle, was shown to be a function of stress, temperature and particle dispersion parameters. When the viscous glide rate is fast, the model gives a shear creep rate, $\dot{\gamma}$ that is a very strong (sinh) function of stress, temperature and inter-particle spacing. A further departure from the Ansell-Weertman model is that it incorporates the suggestion of Ion et al [11] that the creeping matrix progressively transfers load to the non-creeping particles, which are assumed in this case to deform elastically. The proposal is that this is the sole mechanism of primary creep in precipitation-strengthened crystals far from athermal yield. For the particular case where the microstructure of the material is completely stable, the instantaneous uniaxial creep rate $\dot{\varepsilon}$ and the normalised back stress caused by the particles $H=\sigma_{b} / \sigma$ can be described by the two coupled differential equations:

$\dot{\varepsilon}=\dot{\varepsilon}_{0} \sinh \left(\sigma(1-H) / \sigma_{0}\right)$
$\dot{H}=(h / \sigma)\left(1-H / H^{*}\right) \dot{\varepsilon}$

There are four parameters in these equations, all of which are directly related to physical/ geometrical constants or quantitative measures of the microstructure. These are the dislocation density $\rho$, jog density $c_{j}$, volume diffusivity $D_{v}=D_{0} e^{-Q_{d, j} / R T}$, particle volume fraction $\phi_{p}$, the inter-particle (surface to surface) spacing, $\lambda_{p}, E$ the (assumed equal, matrix/particle) Youngs modulus and the mean Taylor factor $\bar{M}, R$ is the Gas Constant and $\mathrm{T}$ is the temperature in K. :

$\dot{\varepsilon}_{0}=2 \rho_{i} \phi_{p}^{1 / 2} \bar{M}^{-1}\left(1-\phi_{p}\right)\left([\pi / 4]^{1 / 2}-\phi_{p}^{1 / 2}\right) c_{j} D_{v}=\dot{\varepsilon}_{0}{ }^{\prime} e^{-Q_{d / j} / R T}$

$\sigma_{0}=K_{C F}\left(\phi_{p}\right) \bar{M} k T / b^{2} \lambda_{p}$

$h^{\prime}=E \phi_{p}$

$H^{*}=2 \phi_{p} /\left(1+2 \phi_{p}\right)$.
A constraint factor $K_{C F}\left(\phi_{p}\right)$ has been incorporated to take account of the 3-D stress fields due to the close approach of cubical particles in high volume fraction alloys. Its magnitude has been calculated using a formulation by Pollock and Argon [15] reexpressed here as a function of particle volume fraction:

$$
\begin{aligned}
& K_{C F}\left(\phi_{p}\right)=1+2 \phi_{p}^{1 / 3} / 3 \sqrt{3 \pi}\left(1-\phi_{p}^{1 / 3}\right) \text { for } \quad \phi_{p} \geq 0.3 \quad \text { and } \\
& K_{C F}\left(\phi_{p}\right)=1 \text { for } \phi_{p}<0.3 .
\end{aligned}
$$

The above set of equations naturally leads to a decreasing creep rate with increasing strain (primary creep) until a steady state is reached at constant stress.

However, the microstructure of nickel-base superalloys is not stable at elevated temperature. The model can be extended to account for the dynamic nature of the material. [16]

i. The equilibrium volume fraction of $\gamma^{\prime}$ varies with temperature and is strongly dependent on the solvus temperature of the alloy under consideration $T_{s}$. Its major influence is through the magnitude of the isotropic strength parameter $\sigma_{0}$.

ii. The particle-dispersion coarsens during service. Assuming Ostwald ripening to occur by volume diffusion with a kinetic rate constant $K_{p}$, the coarsening rate can be shown to be given by $\dot{D}_{p}=K_{p}\left(1-D_{p}\right)^{4} / 3$ that modifies $\sigma_{0}$ to $\sigma_{0}\left(1-D_{p}\right)$ where $D_{p}$ is an appropriately defined damage state variable. [17]. Note that $\sigma_{0}$ refers to the initial particle configuration.

iii. As inelastic (creep) strain accumulates, dislocation sources will be activated leading to a progressive increase in dislocation density. This effect has been represented by a damage variable $\dot{D}_{d}=C \dot{\varepsilon}$, where $C$ is a constant and $D_{d}=\left(\rho / \rho_{i}\right)-1$. This leads to an increase in the pre-sinh term by a factor of $\left(1+D_{d}\right)$.

Thus the dynamic nature of the microstructure can be incorporated into the model, expressing the uniaxial creep rate $\dot{\varepsilon}$ as a function of three state variables $\left(H, D_{d}\right.$ and $\left.D_{p}\right)$ through its expansion from two to the following four coupled differential equations:

$$
\begin{aligned}
& \dot{\varepsilon}=\dot{\varepsilon}_{0}\left(1+D_{d}\right) e^{-Q_{d / j} / R T} \sinh \left[\frac{\sigma(1-H)}{\sigma_{0}\left(1-D_{p}\right)}\right] \\
& \dot{H}=(h / \sigma)\left(1-H / H^{*}\right) \dot{\varepsilon} \\
& \dot{D}_{d}=C \dot{\varepsilon} \\
& \dot{D}_{p}=\frac{K_{p}^{\prime}}{3}\left(1-D_{p}\right)^{4}
\end{aligned}
$$

This set of constitutive equations requires 10 parameters to be determined in order to predict the full variable temperature/stress behaviour when the hardening and two types of damage are in operation:

$\dot{\varepsilon}_{0}^{\prime}, Q_{d / j}, \sigma_{0}, \Delta H_{s}, T_{s}, h^{\prime}, H^{*}, Q_{p}, K_{p}^{\prime}, C$. 
At this point, no consideration has been given to the effects of grain boundary cavitation. Consequently, it is appropriate to single- and directionally solidified crystals and to polycrystalline alloys that deform to large strains where the life is not significantly affected by cavitation or cracking. Development of the model to account for so-called creep brittle polycrystalline alloys will be described in the appropriate section below.

\section{Application of the basic model}

The model has been used to represent a creep database for the superalloy IN738LC in the directionally solidified form in which strain/time plots are available at $750^{\circ} \mathrm{C}, 850^{\circ} \mathrm{C}$ and $950^{\circ} \mathrm{C}$ for lives to over 20,000 hours. The first step in calibrating the model was to estimate the various constants, physical and microstructural, appropriate to this alloy. These are listed in Table 1. Some of the quantities are known with some accuracy, since this is an alloy that has been extensively characterised [18]. These include the volume fraction, initial size distribution and the coarsening characteristics of the $\gamma^{\prime}$ precipitate. Others, such as the dislocation density and the jog formation characteristics are subject to some uncertainty. Although the $\gamma^{\prime}$ distribution is bimodal in this alloy, calculations indicate that it is the small particles that determine the magnitude of the strength parameter $\sigma_{0}$.

The physical and microstructural parameters are then used to evaluate the values of the operational model parameters associated with equation- set 2 . The a priori set of parameters calculated from the information in Table 1 is shown in the first line of Table 2. The coarsening parameter is determined by the average particle size. Using these values as initial estimates, a numerical optimisation procedure was used to fine-tune the parameters to give an optimum fit to the rupture life data for the entire database. The optimised values of the model parameters are also shown in Table 2. The major difference is in the value of the characteristic creep rate, which is a factor of 25 lower than the initial estimate. However, this is the parameter that is dependent on the dislocation density and jog density, neither of which is known with any precision. A comparison of the measured and computed rupture lives and minimum creep rates is shown in Figure 1.

Table 1 Estimates of physical constants and microstructural parameters appropriate to IN738LC.

$\begin{array}{ll}\begin{array}{l}\text { Initial dislocation density } \\ \text { Burger's vector }\end{array} & \begin{array}{l}10^{10} \mathrm{~m}^{-2} \\ 2.5 \times 10^{-10} \mathrm{~m}\end{array} \\ \gamma^{\prime} \text { Volume Fraction and mean size } & \begin{array}{l}\text { large } 20 \%-/ 250 \mathrm{~nm} \\ \text { small } 25 \%-/ 90 \mathrm{~nm}\end{array} \\ \begin{array}{l}\text { Jog density (pre-exponential coefficient) } \\ \text { Volume diffusion (pre-exponential } \\ \text { coefficient) }\end{array} & 1.9 \times 10^{-4} \mathrm{~m}^{2} \mathrm{~s}^{-1} \\ \begin{array}{l}\text { Volume diffusion activation energy } \\ \text { Coarsening activation energy }\end{array} & 284 \mathrm{kJmol}^{-1} \\ \begin{array}{l}\text { Coarsening rate (pre-exponential } \\ \text { coefficient) }\end{array} & 305 \mathrm{kJmol}^{-1} \\ \end{array}$

No creep curves have been analysed at this point of the model calibration. It is of interest to compare the strain-time evolution calculated using equation-set 2 and the optimised parameters. Figure 2 shows creep data for two tests at $850^{\circ} \mathrm{C}$ with a stress of $170 \mathrm{MPa}$, to indicate the experimental scatter, together with the model prediction. The general shapes of the creep curves, which is determined by the evolution of the state variables $H, . D_{d}$ and $D_{p}$, has been well represented. These variables are determined by material parameters that are known with reasonable accuracy. It is the timescale over which the curve develops that has had to be fine-tuned, and this depends on $\rho_{i}$ and $c_{j}$, which are very difficult to estimate. It is important to note that the model is being assessed on a form of the alloy that has high creep ductiliy where creep cavitation can be ignored. In the conventionally cast form of IN738LC, lower creep strains, shorter lives and higher minimum creep rates are observed as illustrated in Figure 2. This will be discussed further below.
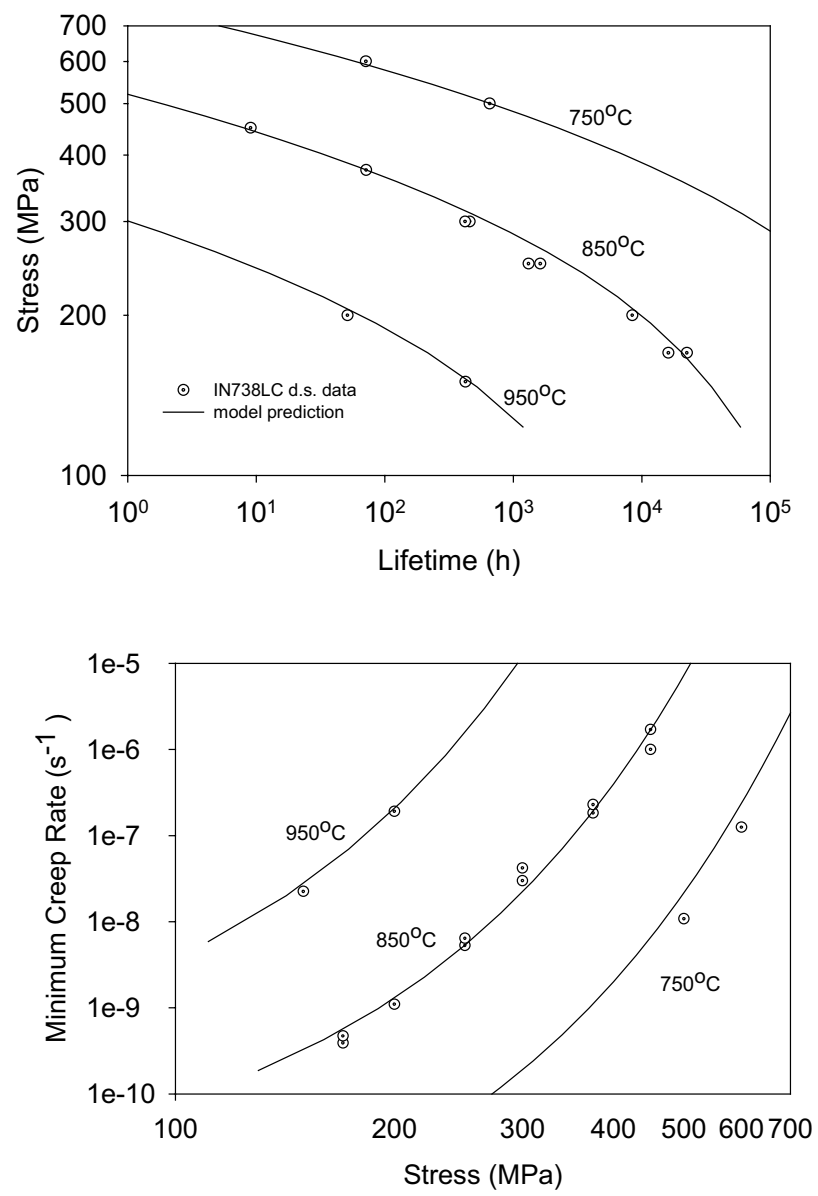

Figure 1 Comparison of IN738LC DS stress rupture and minimum creep rate data with model predictions using the optimised model parameters 
Table 2 Macroscopic model parameters for IN738LC theoretically calculated from the data in Table 1 and optimised to give the best fit to the creep data.

\begin{tabular}{|c|c|c|c|c|c|c|c|c|c|c|}
\hline & $\begin{array}{c}\dot{\varepsilon}_{0}^{\prime} \\
\left(s^{-1}\right)\end{array}$ & $\begin{array}{c}Q_{d / j} \\
(\mathrm{~kJ} / \mathrm{mol})\end{array}$ & $\begin{array}{c}\sigma_{0} \\
(\mathrm{MPa})\end{array}$ & $\begin{array}{c}\Delta \mathrm{H}_{\mathrm{s}} \\
(\mathrm{kJ} / \mathrm{mol})\end{array}$ & $\begin{array}{c}T_{s} \\
(\mathrm{~K})\end{array}$ & $\begin{array}{c}h^{\prime} \\
(\mathrm{MPa})\end{array}$ & $\mathrm{H}^{*}$ & $\mathrm{C}$ & $\begin{array}{c}K_{p}^{\prime} \\
\left(s^{-1}\right)\end{array}$ & $\begin{array}{c}Q_{p} \\
(\mathrm{~kJ} / \mathrm{mol})\end{array}$ \\
\hline Theoretical & $1.01 \times 10^{5}$ & 311 & 33 & 49.83 & 1394 & $7.2 \times 10^{4}$ & 0.47 & 67 & $10^{6}$ & 305 \\
\hline Optimised & $4.44 \times 10^{3}$ & 316 & 33 & 49.83 & 1394 & $7.2 \times 10^{4}$ & 0.47 & 67 & $10^{6}$ & 305 \\
\hline
\end{tabular}

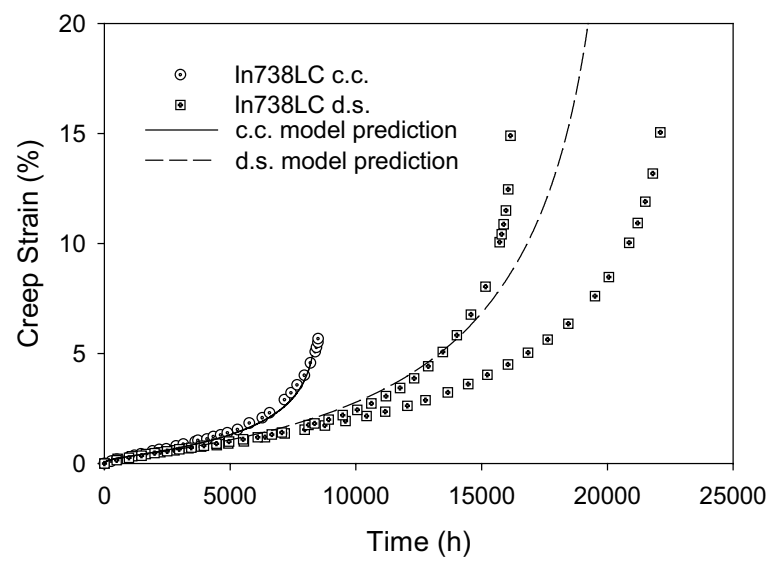

Figure 2 Comparison of simulated and experimental creep curves for IN738LC.

\section{Extrapolation to other alloys}

As indicated above, the historical development of nickel-base superalloys has largely been achieved by control of the $\gamma^{\prime}$ solvus and particle volume fraction and size. Since the basis of the model is to relate the creep behaviour explicitly to quantitative measures of these aspects of microstructure, it is of interest to explore the extent to which the creep behaviour of different generations of superalloys can be represented by the model. Figure 3 compares the $850^{\circ} \mathrm{C}$ stress rupture data for IN738LC superalloy with those of a wrought polycrystal (Nimonic 90) and a single crystal (CMSX4).

Nimonic90 is a wrought alloy containing $25 \%$ volume fraction of $\gamma^{\prime}$ with an initial mean diameter of about $28 \mathrm{~nm}$. CMSX4 is a $2^{\text {nd }}$ generation single crystal superalloy, which has $65-70 \%$ volume fraction of $\gamma^{\prime}$ of initial size of $250 \mu \mathrm{m}$. Simulations were run for these alloys using the parameters listed in Table 1 with the exception of material specific values for $\gamma^{\prime}$ volume fraction and size calculated at the appropriate temperature $\left(850^{\circ} \mathrm{C}\right)$.

The simulated and measured stress rupture behaviour of the three alloys is shown in Figure 3. Although there are details that are not represented by the model, it clearly captures the substantial improvement in creep strength of these different generations of superalloy. There are special factors that will have to be taken into account to provide a fuller representation of creep in the individual alloys. For example, the data for CMSX4 for different crystallographic orientations show significant differences and no account is taken of the role of rhenium, which is thought to suppress dislocation climb- and particle coarsening-rates. The underestimate of long-term lives for Nimonic 90 is more problematical. Either the effect of particle coarsening has been over-estimated or the degree of dislocation- softening has been attenuated by a thermal recovery process not considered in the model. Nevertheless, the ability of the model to encompass different generations of alloys is very encouraging.

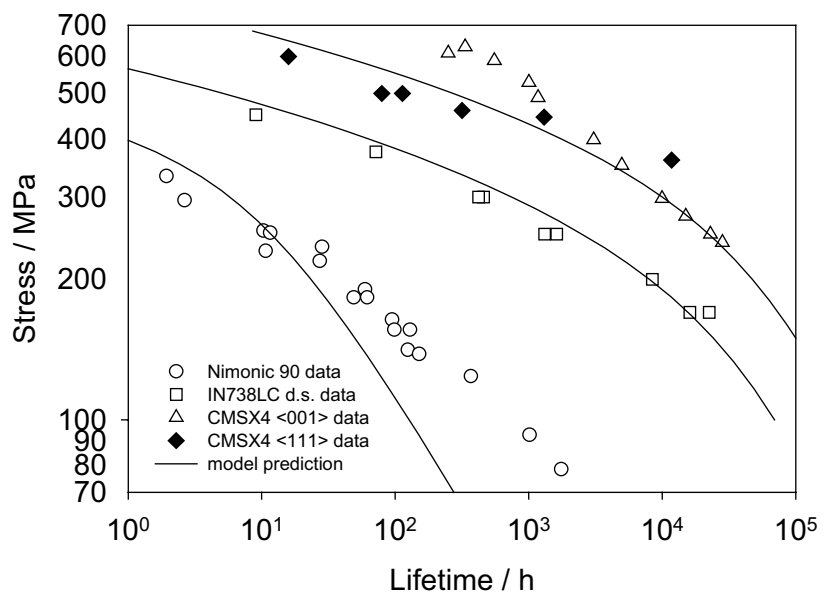

Figure 3 Comparison of model predictions with measured creep lifetimes at $850^{\circ} \mathrm{C}$ for three alloys with different $\gamma^{\prime}$ volume fractions and particle size

\section{Effect of Grain Boundary Cavitation}

The original formulation of continuum damage mechanics by Kachanov [9] to account for creep strain trajectories never explicitly identified the damage mechanism responsible for tertiary creep, although it was interpreted as cavitation for many years. In that first treatment by Kachanov, failure was assumed to occur when a dimensionless damage parameter increased from 0 to 1 . The damage did not affect the creep rate, but determined the (potentially varying) magnitude of the creep strain at failure. Kachanov does not predict tertiary creep for conditions of constant stress. Rabotnov's contribution [10] was to couple the development of damage with the creep rate through an increase in stress associated with a reduction in load bearing area as the damage, by implication cavitation, developed. This leads to an accelerating creep rate (i.e. tertiary creep).

There have been many studies of creep cavitation, both experimental and theoretical; it is beyond the scope of this paper to provide a detailed review. Rather, we summarise the relevant aspects that can be incorporated into the present model. Creep 
cavities develop on grain boundaries that are subject to a mechanical traction; i.e. those normal to a tensile stress. Consequently, inelastic deformation within the alloy can become highly spatially heterogeneous. The total strain in the neighbourhood of such transverse boundaries is composed of dilatory displacements due to stress-directed diffusional growth of the cavities, inelastic displacements due to creep and spatially heterogeneous elastic displacements due to stress redistribution. Remote from the transverse boundaries, displacements are elastic plus inelastic. There are two extremes of behaviour:

a. Unconstrained cavity growth in which the creep displacement rates within the uncavitated regions are much faster than the displacement rates due to cavity growth. The cavities are then free to grow at the rate determined by the (essentially applied) stress directed diffusion. This is equivalent to the Kachanov formulation where the macroscopic creep deformation is unaffected by cavitation, but fracture occurs when the transverse grain boundaries are fully cavitated and link up to cause fracture.

b. Constrained cavity growth occurs when the creep displacement rates within the uncavitated regions are slower than those due to cavity growth. In this condition, stress is off-loaded from the fast growing cavitated boundary regions to the uncavitated zones. This increases the creep rate by reducing the effective stress controlling creep and is thus more consistent with the proposal of Rabotnov.

Dyson and Gibbons [19] proposed a simplified method for dealing with the case when grain facets cavitate at a constant rate (nucleation controlled) but with individual cavity growth constrained. An additional damage term $D_{c}$ that couples with the creep rate equation was introduced (Equation 3e). . The geometrical constant $k_{c} \approx 0.33$ is for equiaxed grains and $\varepsilon_{f, \text { min }}$ is the material-specific minimum creep failure strain. The expanded equation set is given by Eq.3:

$\begin{array}{ll}\dot{\varepsilon}=\dot{\varepsilon}_{0}^{\prime}\left(1+D_{d}\right) \exp \left[-\frac{Q_{d / j}}{R T}\right] \sinh \left[\frac{\sigma(1-H)}{\sigma_{0}\left(1-D_{p}\right)\left(1-D_{c}\right)}\right] & \\ \dot{H}=\frac{h^{\prime}}{\sigma}\left(1-\frac{H}{H^{*}}\right) \dot{\varepsilon} & {[3 \mathrm{~b}]} \\ \dot{D}_{d}=C \dot{\varepsilon} & {[3 \mathrm{c}]} \\ \dot{D}_{p}=\frac{K_{p}}{3}\left(1-D_{p}\right)^{4} & {[3 \mathrm{~d}]} \\ \dot{D}_{c}=\frac{k_{c}}{\varepsilon_{f}} \dot{\varepsilon} & {[3 \mathrm{e}]}\end{array}$

Numerically integrating equation-set 3 with the optimised parameter set determined for directionally solidified IN738LC, together with values of $k_{c}=0.33 k=0.33$ and $\varepsilon_{f}=4.9 \%$ (the

lower bound to the creep strain found in IN738cc; see Fig.2), simulates the long term stress-rupture behaviour of the conventionally cast alloy shown in Fig. 4 very well. It is poor at higher stress levels where conventionally-cast and directionallysolidified data converge and which can therefore be modelled by the original optimised parameter-set. The reason for this, as shown below, is because there is a transition between constrained and unconstrained cavity growth as stress increases, making the approximations in equation-set 3 inappropriate.

Dyson [20] has modelled the transition between unconstrained and constrained cavity growth in terms of a two-bar structure between sound, uncavitated alloy $\alpha$ and cavitated alloy $\beta$ (see Figure 5). Region $\alpha$ of volume fraction $\phi_{\alpha}$ is taken as being described by equation-set 2 . The cavitated region, of volume fraction $\left(1-\phi_{\alpha}\right)$, experiences two contributions to strain: inelastic flow as in the $\alpha$ region, and a dilatory contribution due to the diffusive growth of grain boundary cavities. Using the kinetic equation derived by Speight and Beeré [21], it was possible to model the transition between constrained and unconstrained cavity growth in a commercial aluminium alloy.

Basoalto and Dyson [22] are currently improving and using this approach to model stress rupture behaviour for conventionally cast IN738LC. Figure 6(a) shows the predicted variation of ductility with lifetime and Fig.6(b), the corresponding stress/ lifetime plot. The model's prediction of an increasing failure strain for short life tests, beyond a critical stress (due to increasing loss of constraint) correlates with the stress/lifetime data of the two alloy-variants converging.

In Figure 6a the model overestimates the experimental ductility. This is almost certainly due to the fact that it currently excludes the possibility of faster cavity growth rates in the unconstrained regime due to matrix strain rate effects. [23,24,25]

In previous versions of this [16] and other [5,6,7,8] models of creep curve shapes, deformation has been terminated at a predetermined strain that has been obtained experimentally. We believe that this is the first model that predicts failure strain whuich varies with stress and temperature.

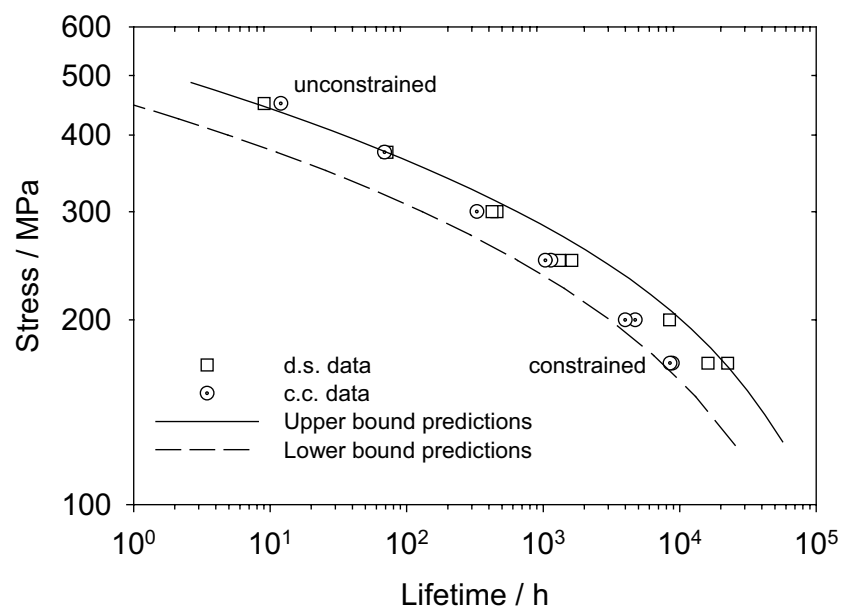

Figure 4 Comparison of stress rupture lives for conventionally cast and directionally solidified IN738LC with predictions for constrained (Equation Set 3) and unconstrained cavity growth (Equation Set 2). 


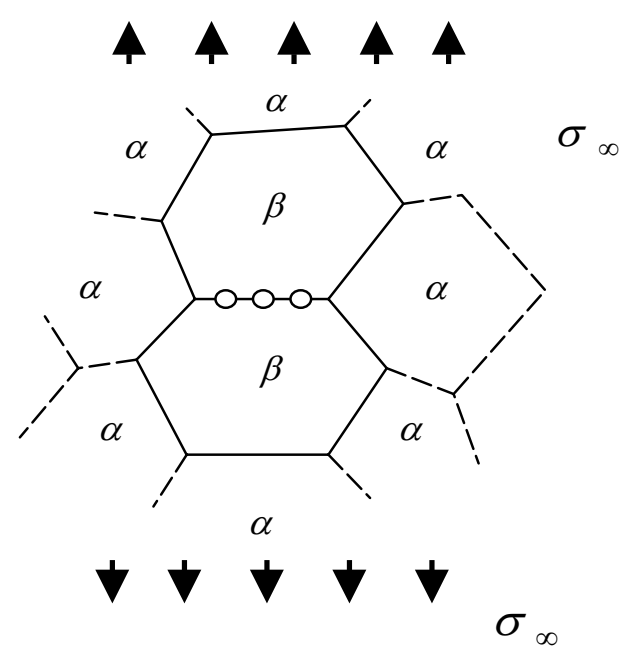

Figure 5 Schematic showing $\alpha$ and $\beta$ grains unaffected and affected by the development of grain boundary cavities respectively.
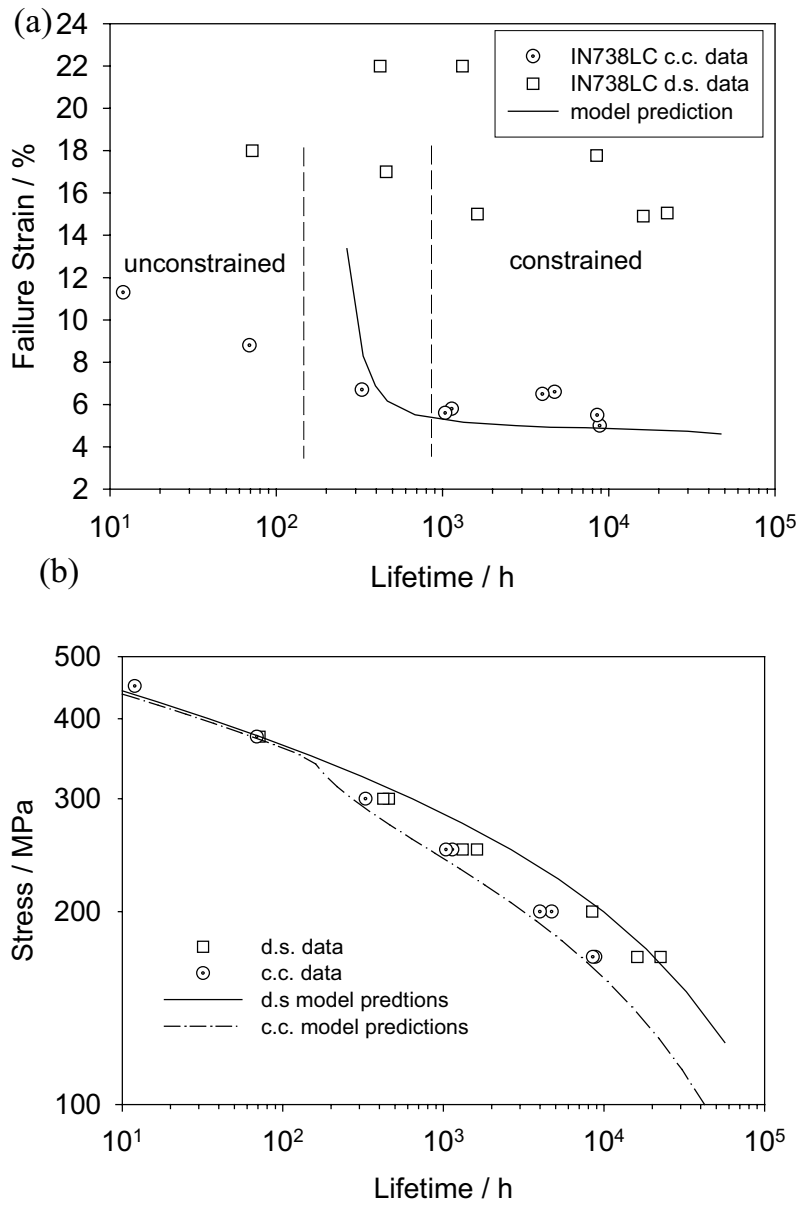

Figure 6 Comparison of (a)stress rupture lives and (b) creep failure strain for conventionally cast and directionally solidified IN738LC with predictions for a transition between constrained and unconstrained cavity growth.

\section{Application to Turbine Disc Alloys}

The potential of representing the creep behaviour turbine disc alloys using the model described above has been investigated as part as part of the DARPA Accelerated Insertion of Materials (AIM) programme. [3] The work has been carried out in conjunction with GE Aircraft Engines, Pratt and Whitney and a consortium of university research groups. Two representative powder alloys have been investigated - Rene88DT with a supersolvus heat treatment and IN100 with a subsolvus heat treatment. Since creep has not been perceived in the past as being a problem for gas turbine discs, there is very little information on their creep behaviour. Also, since these alloys have been developed with optimum yield stress, they have quite different microstructures from the blade alloys discussed above. The first stage of the investigation was to experimentally characterise the microstructure and creep behaviour of the two alloys.

The basic microstructural characteristics of the two alloys in the as-heat treated condition are summarised in Table 3. The subsolvus IN100 has a grain size of about $5 \mu \mathrm{m}$ and three distinct populations of $\gamma^{\prime}$ particles with a combined volume fraction of 0.56 . Rene88DT has a larger grain size of $25 \mu \mathrm{m}$ and a smaller volume fraction of $\gamma^{\prime}$ particles of 0.36 distributed as a bimodal distribution with none of the primary $\gamma^{\prime}$ particles present in IN100. However, in both cases the grain sizes are much smaller than in turbine blade alloys. Although the particle sizes can be measured with some precision, there are no reliable techniques available for measuring the volume fractions of the tertiary precipitate. Consequently, the tertiary $\gamma^{\prime}$ volume fractions have been estimated as the difference between the total $\gamma^{\prime}$ content, determined by Thermocalc calculation, and the sum of the measured primary and secondary $\gamma^{\prime}$ volume fractions.

The shapes of the creep curves for the two alloys produced with uniaxial tensile stresses were very similar, and quite different from those of turbine blade alloys. Figure 7(a) is quite typical, showing no primary creep, imperceptible creep over about $30 \%$ of the life followed by a progressive increase in creep rate to failure at a strain of $10 \%$ or more. Close examination of the initial stages of the longer-term creep curves showed that there was a period of negative creep as shown in Figure 7(b). The creep rupture lives of the two alloys at 649 and $704^{\circ} \mathrm{C}$ are shown in Figure 8. In spite of the large difference in $\gamma^{\prime}$ volume fractions in the two alloys, they display similar creep lives at $649^{\circ} \mathrm{C}$. More surprisingly, Rene88DT, which has a smaller $\gamma^{\prime}$ content than IN100, has significantly superior stress rupture lives at $704^{\circ} \mathrm{C}$.

Before attempting to apply the model to these data, it is necessary to understand why the creep behaviour of the disc alloys is so different from that of blade materials. Also, the retention of creep resistance of Rene88DT relative to IN100 must be rationalised. To clarify these issues, a series of diagnostic tests have been undertaken in order to guide the development of the model to represent the creep behaviour of the disc alloys. The rationale behind this study is described in detail by Sondhi et al. [26] 

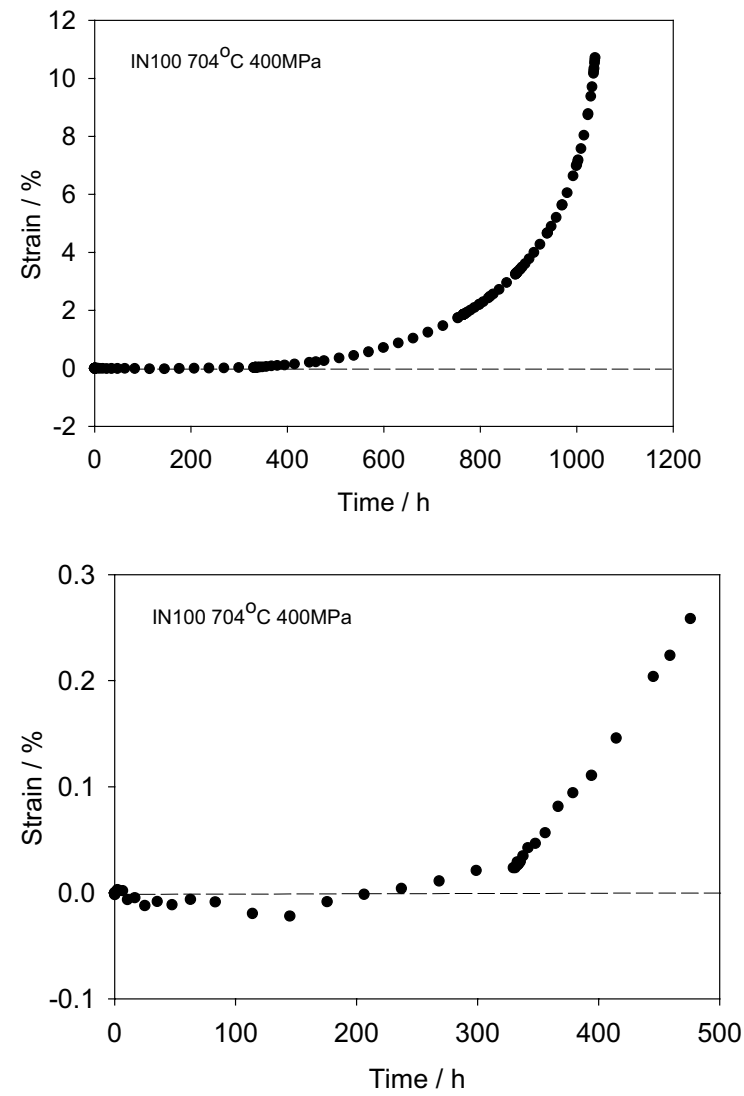

Figure 7 Creep curve for IN100 tested in tension at $704^{\circ} \mathrm{C}$ and $400 \mathrm{MPa}$ (a) full creep curve and (b) enlargement of the early part showing negative creep.

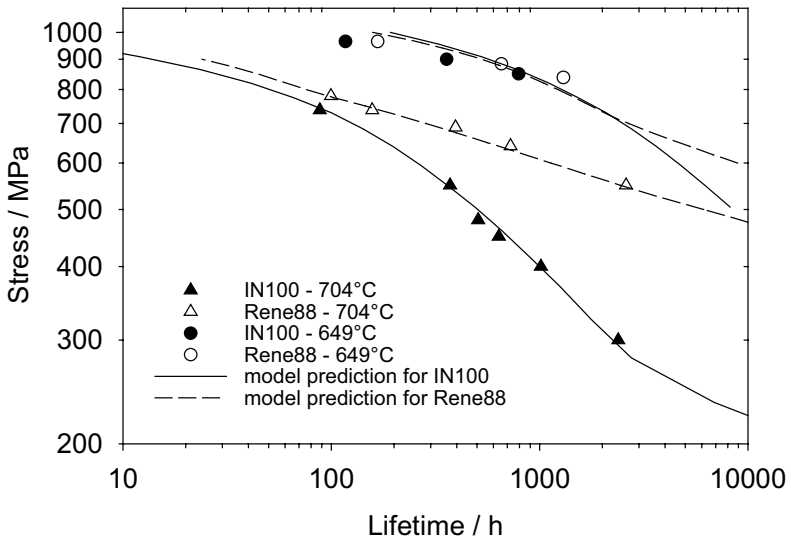

Figure 8 Comparison of creep lives in tension as a function of stress for IN100 and Rene88DT at 649 and $704^{\circ} \mathrm{C}$.

The diagnostic tests undertaken were:

i. Creep specimens were monitored in the absence of an applied stress at $704^{\circ} \mathrm{C}$. Both alloys exhibited progressive linear shrinkage strains of $\approx 0.1 \%$ over periods of several hundreds of hours. Henry [27] has shown that the density of Rene88DT increases during heat treatment. ii. A comparison was made of the creep response in axial tension and compression loading. Figure 9 is typical of the results obtained on both alloys. In compression there is a distinct primary creep that is absent in tension, with up to $1 \%$ strain being accumulated before there is any perceptible strain in tension. If this tension/compression asymmetry were the linear superposition of creep strain and shrinkage due to an unspecified microstructural change then the difference between the two curves would be twice the shrinkage as a function of time. It is clear that the tension-compression asymmetry is much greater than the sum of the two effects (Figure 9).

iii. The effect of prior heat treatment at the test temperature is shown in Figure 10 for both tension and compression loading. There are two quite distinct effects in the short and the long term. In the case shown for a prior heat treatment of 600 hours at $704^{\circ} \mathrm{C}$, the initial tension compression asymmetry has been completely eliminated. Thus the initial creep strength in compression is increased, whereas that in tension has been reduced. However, in the later stages of creep prior heat treatment leads to increased creep rates relative to the as received alloys.

iv. The results of ageing heat treatment on the alloy microstructures have also been examined. The only significant change observed was a coarsening of the tertiary $\gamma^{\prime}$ particles. This is consistent with previously published work on the coarsening of $\gamma^{\prime}$, which is reflected in the coarsening constants incorporated in the model and listed in Table 2. Assuming that the normal $r^{3}$ LSW coarsening law applies [18,29], $\dot{r}$ for the tertiary particles will be $10^{2}$ and $10^{4}$ faster than for the secondary and primary particles respectively. It would be expected that the tertiary $\gamma^{\prime}$ would eventually dissolve and reprecipitate on the secondary particles.

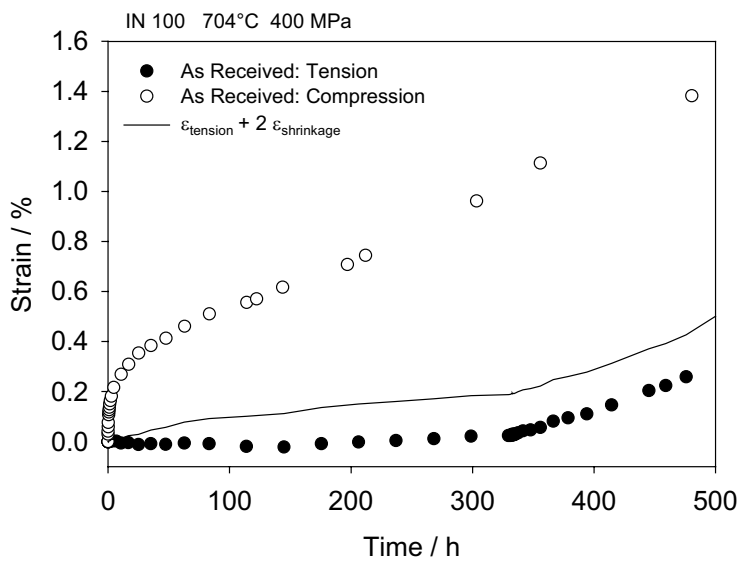

Figure 9 Comparison of the initial stages of creep curves obtained in tension and compression for IN100 tested in constant load at $704^{\circ} \mathrm{C}$ and $400 \mathrm{MPa}$. The curve computed from the

Thermal ageing of the alloys has two important effects:

a. The volume misfit between particle and matrix can be relaxed by a combination of loss of coherency and mass transport. Complementary to the matrix compressive stress, the particle will be in tension. The initial value of $\mathrm{H}$ in the model will no longer be zero, and will evolve with both accumulated creep strain and with recovery of the internal stress. In the present analysis we assume that the stress is relaxed only by 
diffusional mass transport. The effect of relaxation of the stress will be to attenuate the tension/compression asymmetry.

measured tensile strain and twice the axial contraction in the absence of stress is shown for comparison.

The model has been expanded to take this effect into consideration giving the expanded set of Equations:

$\begin{array}{ll}\dot{\varepsilon}=\dot{\varepsilon}_{\text {creep }}+\dot{\varepsilon}_{\text {thermal }} & \text { [4a }] \\ \dot{\varepsilon}_{\text {creep }}=\dot{\varepsilon}_{0}\left(1+D_{d}\right) e^{-Q_{d / j} / R T} \sinh \left[\frac{\sigma(1-H)}{\sigma_{0}\left(1-D_{p}\right)}\right] & {[4 \mathrm{~b}]} \\ \dot{\varepsilon}_{\text {thernal }}=A e^{-Q_{D} / R T} \sigma_{\text {in }} & {[4 \mathrm{c}]} \\ \dot{H}=(h / \sigma)\left(1-H / H^{*}\right) \dot{\varepsilon}_{\text {creep }}-E \dot{\varepsilon}_{\text {thermal }} & {[4 \mathrm{~d}]} \\ \dot{D}_{d}=C \dot{\varepsilon} & {[4 \mathrm{e}]} \\ \dot{D}_{p}=\frac{K_{p}^{\prime}}{3}\left(1-D_{p}\right)^{4} & {[4 \mathrm{f}]}\end{array}$

The $\gamma^{\prime}$ will coarsen, particularly the finest particles, and this will affect the creep properties in both tension and compression. This is complicated by the reduction in volume fraction of $\gamma^{\prime}$

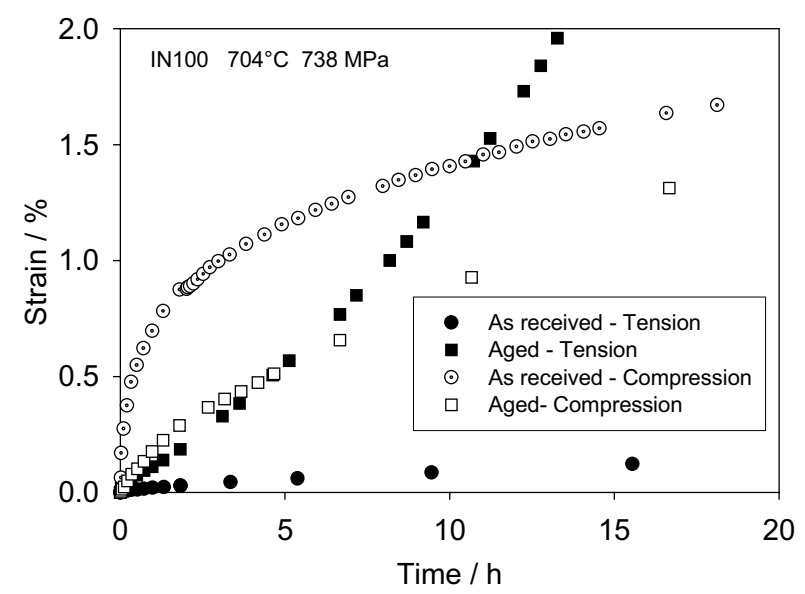

with increasing temperature, which is determined by the slope of the solvus. In the present analysis we assume that at elevated temperatures the dissolution of $\gamma^{\prime}$ is entirely accommodated by a reduction in the volume fraction of the tertiary precipitate. The temperature dependence of volume fraction is calculated using an empirical relationship for the $\gamma-\gamma^{\prime}$ equilibrium in nickel-base superalloys. This allows the model to be used to calculate the intrinsic creep behaviour associated with the secondary and tertiary particles to be determined. Sondhi et al. [26] have calculated the values of $\sigma_{0}$ associated with each population as function of temperature (Table 4) and the other parameters are listed in Table 5. As the tertiary particles coarsen, the relative contributions of the different populations of particles to the creep resistance will change. This leads to the stress-rupture plots having a sigmoidal shape, the two bounds corresponding to the creep performance associated with small and the large precipitate particles. The separation of these bounds depends on the values of $\sigma_{0}$ for the two populations and the transition between them will be determined by the coarsening kinetics of $\gamma^{\prime}$ at that temperature.

Figure 10 Effect of prior heat treatment on (a) initial stages of compression and tension creep curves and (b) longer term compression creep curves for IN100 tested at $704^{\circ} \mathrm{C}$ and $738 \mathrm{MPa}$.

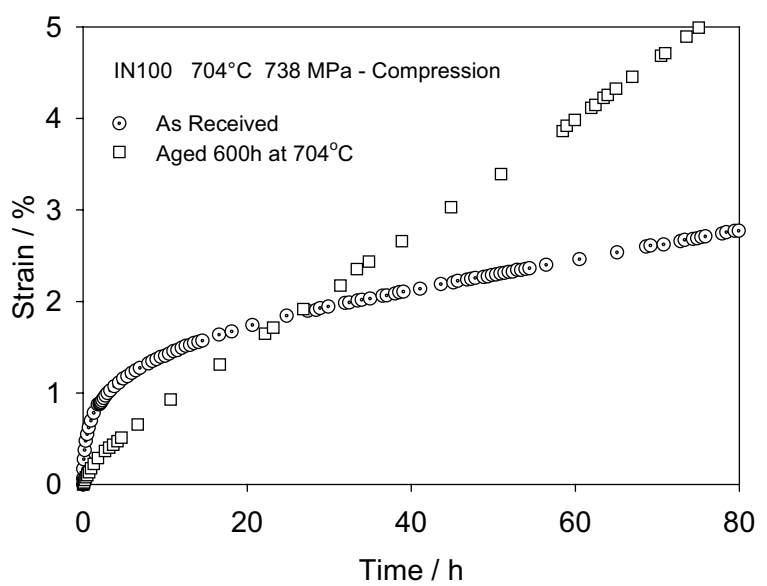

Table 3 Summary of the microstructural characteristics of the turbine disc alloys studied.

\begin{tabular}{|l|c|lccc|}
\hline & Grain size $\mu \mathrm{m}$ & $\gamma^{\prime}$ population: & Primary & Secondary & Tertiary \\
& & & & & \\
\hline IN100 & 5 & size $(\mathrm{nm})$ & 1000 & 200 & 10 to 20 \\
& & volume fraction & 20 & 34 & 6 \\
\hline Rene88DT & 25 & size $(\mathrm{nm})$ & & 120 & $<15$ \\
& & volume fraction & & 33 & 7.2 \\
\end{tabular}


Table 4 Calculated values of $\sigma_{0}$ associated with each population of $\gamma^{\prime}$ particles as a function of temperature.

\begin{tabular}{|c|c|c|c|}
\hline \multirow{2}{*}{ Alloy } & \multirow{2}{*}{$\mathrm{T}\left({ }^{\circ} \mathrm{C}\right)$} & \multicolumn{2}{|c|}{$\sigma_{0}(\mathrm{MPa})$} \\
\cline { 3 - 4 } & & Secondary & Tertiary \\
\hline \multirow{3}{*}{ IN100 } & 649 & 20.36 & 51.01 \\
\cline { 2 - 4 } & 704 & 19.71 & 44.17 \\
\cline { 2 - 4 } & 760 & 19.41 & 31.12 \\
\hline Rene88DT & 649 & 38.89 & 46.68 \\
\cline { 2 - 4 } & 704 & 39.50 & 42.79 \\
\hline
\end{tabular}

The model captures the principal features of the complex creep behaviour of the disc alloys:

- A comparison of experimental and simulated creep curves (Figure 11 ) shows that the model represents the unusual shapes of creep curves for turbine disc alloys. In particular, a period of negative creep is predicted for the longer-term test at $704^{\circ} \mathrm{C}$ and $400 \mathrm{MPa}$.

- Figure 12, which shows simulations of tension and compression creep with and without prior heat treatment, should be compared with Figure 10. Elimination of the initial internal stress by ageing has removed the initial tension/compression asymmetry. However, coarsening of the tertiary $\gamma^{\prime}$ has reduced the creep resistance both in tension and compression.

- Calculated rupture lives for the two alloys are shown with the experimental data as continuous curves in Figure 8. The reason that IN100 shows a greater fall in creep strength with increasing temperature than Rene88DT is not due to it being less stable microstructurally. Rather, the secondary $\gamma^{\prime}$ in Rene88DT, being significantly finer, provides significantly greater creep resistance than in IN100. Consequently, as the tertiary precipitate coarsens and dissolves, the sigmoidal limits in the stress rupture behaviour are close together in Rene88DT.

Although the model appears to represent the creep behaviour of the disc alloys reasonably well, the original assumption of plastic deformation being restricted to the matrix is not valid in these materials. There is ample evidence of extensive cutting of the $\gamma^{\prime}$ by dislocations [28] particularly as the short-term yield stress is approached in peak-aged or under-aged alloys. A future version of the model will incorporate the effects of particlecutting but suffice to say here that it weakens the alloy in creep relative to the performance of an alloy containing non-shearable particles.
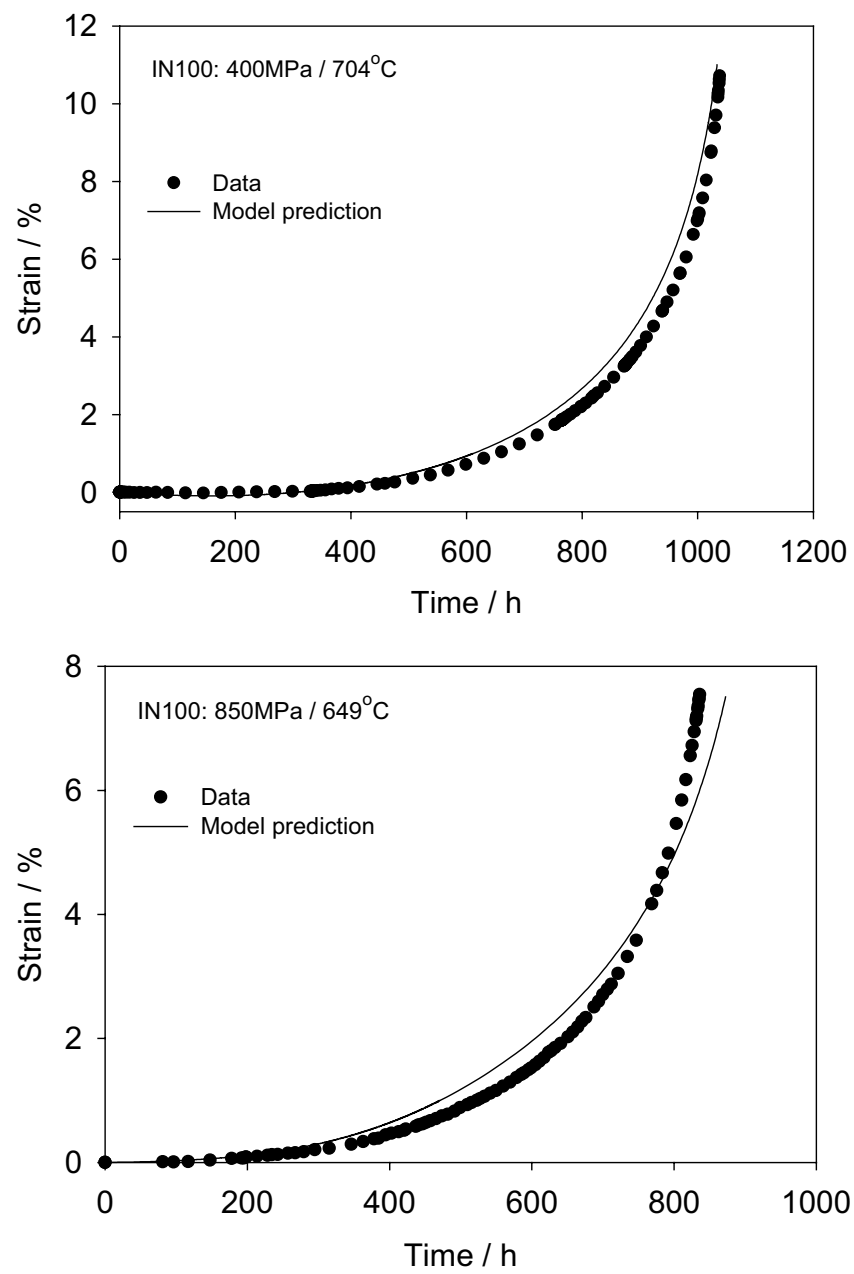

Figure 11: Model predictions of individual creep curves for IN100 at two different test conditions, compared with the experimental data.

Table 5 Model parameters used to simulate the creep behaviour of IN100 and Rene88DT.

\begin{tabular}{|c|c|c|c|c|c|c|c|c|c|c|}
\hline & $\begin{array}{c}\dot{\varepsilon}_{0}^{\prime} \\
\left(s^{-1}\right)\end{array}$ & $\begin{array}{c}Q_{d / j} \\
(\mathrm{~kJ} / \mathrm{mol})\end{array}$ & $\begin{array}{c}\mathrm{A} \\
(\mathrm{MPa})^{-1}\end{array}$ & $\begin{array}{c}\Delta \mathrm{H}_{\mathrm{s}} \\
(\mathrm{kJ} / \mathrm{mol})\end{array}$ & $\begin{array}{c}T_{s} \\
(\mathrm{~K})\end{array}$ & $\begin{array}{c}h^{\prime} \\
(\mathrm{MPa})\end{array}$ & $\mathrm{H}^{*}$ & $\mathrm{C}$ & $\begin{array}{c}K_{p}^{\prime} \\
\left(s^{-1}\right)\end{array}$ & $\begin{array}{c}Q_{p} \\
(\mathrm{~kJ} / \mathrm{mol})\end{array}$ \\
\hline Rene88DT & 200 & 310 & 16035 & 49.83 & 1394 & $2.0 \times 10^{4}$ & 0.20 & $0.4 \sigma$ & $10^{6}$ & 280 \\
\hline IN100 & $2.6 \times 10^{3}$ & 310 & 16035 & 49.83 & 1394 & $2.0 \times 10^{4}$ & 0.20 & $0.05 \sigma$ & $10^{6}$ & 280 \\
\hline
\end{tabular}


S.

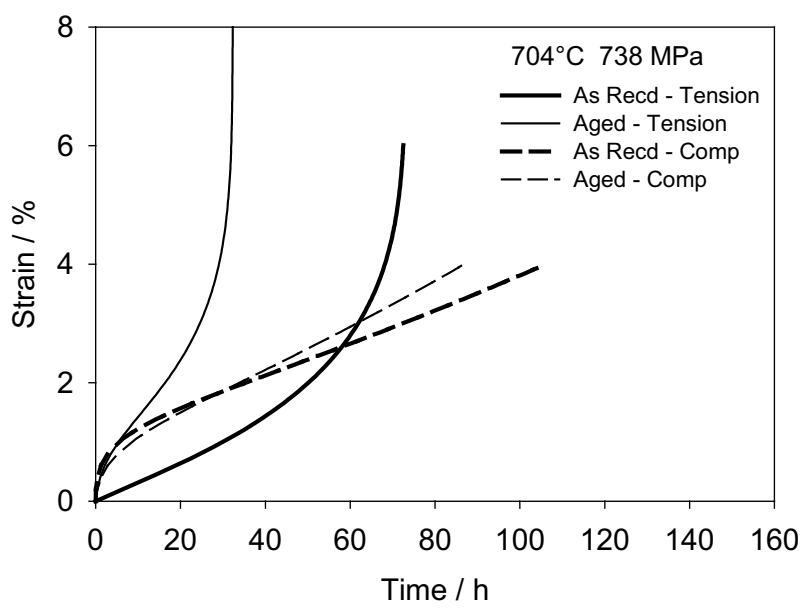

Figure 12 Simulated creep curves for IN100 tested in tension and compression at $704^{\circ} \mathrm{C}$ and $738 \mathrm{MPa}$ in the as-received condition and prior aged for 600 hours at $704^{\circ} \mathrm{C}$.

\section{Conclusions}

1. A model of creep deformation in particle-strengthened alloys that is expressed in terms of microstructural parameters and physical constants has been developed.

2. The model has been applied to a range of $\gamma^{\prime}$ strengthened nickel-base superalloys taking into account the effect of dislocation accumulation, particle coarsening and grain boundary cavitation.

3. By accounting for the transition between unconstrained and constrained cavity growth, creep fracture strains can be calculated and the different creep response of superalloys with equiaxed and columnar grain structures can be predicted.

4. Extension of the model to turbine disc alloys which operate at lower temperatures require the introduction of an initial matrix compressive stress which decays with time and consideration of the differential strengthening associated with multimodal $\gamma^{\prime}$ distributions.

\section{Acknowledgements}

The work reported in this paper was supported by EPSRC (Grant Numbers GR/M93123/01 and GR/R11575/01) and by DARPA as part of the Accelerated Insertion of Materials Programme. The authors acknowledge with thanks materials and discussions with colleagues from GEAE and Pratt \& Whitney and their university support teams.

\section{References}

1. C.T.Sims, "Superalloys: Their Use And Requirements In Advanced Energy Systems", pp1 -24, Proceedings of Superalloys 1976

2. D.N.Duhl in Superalloys II, ed. by C.T.Sims, W.Hagel and N.S.Stoloff, Wiley, New York (1987)

3. http://www.darpa.mil/dso/thrust/matdev/aim/index.html

4. Andrade, E.N. da C., "On the Viscous Flow in Metals and Allied Phenomena”, Proc. R. Soc. London, A, 84, p.1-12, 1910.
5. A.Graham, and K.F.A. Walles, J. Iron Steel Inst., 179 (1955) 105-120.

6. R.W.Evans, J.D.Parker, and B.Wilshire, An extrapolation Procedure for Long-Term Creep Strain and Creep Life Prediction with Special Reference to 1/2Crl/2Mol/4V Ferritic Steels, Recent Advances in Creep and Fracture of Engineering Materials and Structures, Wilshire, B., and Owen, D.R.J., eds., Pineridge Press, Swansea, p. 135-184, 1982.

7. J.L.Chaboche, and G.Rousselier, On the Plastic and Viscoplastic Constitutive Equations - Part II: Application of Internal Variable Concepts to the 316 Stainless Steel, J. Press.Vessel Tech., Vol. 105, p.159, 1983.

8. L.Meric, P.Poubanne and G.Cailletaud, Trans. ASME, J. Eng. Mater.Tech. 113 (1991) 162-170.

9. L.M.Kachanov, On Creep Rupture Time, Izv. Ak. Nauk SSSR Otdel. Tekh. Nauk 8 (1958), 26-31.

10. Y.N.Rabotnov, Creep Problems in Structural Members, Proc. XII IUTAM Congress, Stanford, ed. by Hetenyi \& Vincenti, Springer, (1969)137

11. J.Ion, A. Barbosa, M.F. Ashby, B.F. Dyson, and M. McLean, The Modelling of Creep for Engineering Design I, Report DMA A115, The National Physical Laboratory, Teddington, 1986.

12. G.S.Ansell J. Weertman, Trans AIME, 215 (1959) 838-843.

13. B.F.Dyson and S.Osgerby NPL Report DMA A116 (1993)

14. B.F.Dyson in Creep Behaviour of Advanced Materials for the $21^{\text {st }}$ Century (1999), edited by R S Mishra, A K Mukherjee \& K L Murty, TMS, Warrendale, USA, 3-12.

15. T.M.Pollock and A.S.Argon, Creep Resistance Of CMSX-3 Nickel-Base Superalloy Single-Crystals, Acta Metall. Mater.40 (1992) 1-30.

16. B.F.Dyson and M.McLean, Proc. of IUTAM Symposium on Creep in Structures, 3-7 April 2000 Nagoya. ed. by S.Murakami and N.Ohno, pp 3-16, Kluwer Academic Publishers 2001

17. M.F.Ashby and B.F.Dyson, Creep Damage Mechanics and Micromechanism, in Advances in Fracture Research in Advances in Fracture Research, ed. by S R Valluri et al, (1984) Pergamon Press, 1, 3-30.

18. R.Stevens and P.E.J.Flewitt, Mater. Sci. Eng. 37 (1979) 237-247.

19. B.F.Dyson and T.B.Gibbons, , Acta Metall., 31 (1987) 17-27.

20. B.F.Dyson, in Creep Deformation: Fundamentals and Applications, eds. Mishra et al. TMS, (2002), 309-318.

21. M.V.Speight and W.Beeré, Metal Scienc, 9, (1975), 190191

22. H.C.Basoalto and B.F.Dyson (to be published)

23. F.A.McClintock, J. Appl. Mech. 4 (1968), 363

24. J.W.Hancock, Met. Sci. 10 (1976), 319.

25. A.C.F.Cocks and M.F.Ashby, Progress in Materials Science, 27 (1982), 189-244.

26. S.K.Sondhi, B.F.Dyson, and M.McLean, M., TensionCompression Creep Asymmetry in a Turbine Disc Superalloy: Roles of Internal Stress and Ageing, Acta Mater. In press

27. M.Henry, GE Global Research, Schenectady, N.Y.- private communication.

28. S.Sinharoy, P.Virro-Nic and W.W.Milligan, Metall Mater Trans A32 (2001), 2021-2032.

29. R.A. Ricks, A.J. Porter, and R.C. Ecob, "The Growth of $\gamma^{\prime}$ Precipitates in Nickel-Base Superalloys," Acta. metall., 31 (1983), 43-53. 